\title{
EL DÍA A DÍA DE UNA INSPECTORA DE EDUCACIÓN
}

\section{The day to day of an educational inspector}

\author{
Carmen Romero UreÑA \\ Inspectora de Educación \\ Profesora de la Facultad de Educación y Trabajo Social de la Universidad de Valladolid \\ Correo-e: romurema@gmail.com
}

Recepción: 8 de septiembre de 2018

Envío a informantes: is de septiembre de 2018

Aceptación definitiva: 28 de noviembre de 2018

Todos cuentan la historia por las guerras en las viejas ciudades y por más que pregunto nadie sabe describir la morada donde amasaba pan el panadero y su mujer hilaba.

La historia que nos cuentan es historia de una que otra batalla, pero jamás nos dicen que entre tanto el labrador sembraba.

(Ronda de las viejas ciudades, de A. Ritro y A. Tejada)

Resumen: El artículo trata de recoger una muestra de actuaciones que se realizan en la Inspección de educación en tres momentos del curso, un día de cada trimestre escolar. Está escrito en forma de historia de vida pues tiene el objetivo de ir construyendo el acervo de este colectivo de profesionales tan desconocido y, a la vez, tan fundamental para el sistema educativo.

Se organiza a través de tres partes diferenciadas, la primera es una breve fundamentación de la historia de vida enmarcada en una perspectiva de investigación cualitativa y a través de una metodología biográfica y narrativa; la segunda es el relato de tres días del curso escolar 2017/18, salpicado de reflexiones derivadas de las actuaciones realizadas, y finaliza con una tercera parte con unas conclusiones, fruto de la experiencia diaria de una inspectora de educación.

Palabras Clave: Inspección Educativa; actuaciones; supervisión; asesoramiento; control; evaluación; sistema educativo. 
АвsтRAст: The article tries to collect a sample of actions that are carried out in the education inspection in three moments of the course, one day of each school term. It is written in the form of a life story because it aims to build the collective of this group of professionals that is so unknown and, at the same time, so fundamental to the education system.

It is organized through three differentiated parts, the first is a brief foundation of the history of life framed in a perspective of qualitative research and through a biographical and narrative methodology; the second is the three-day account of the 2017/I8 school year, which is peppered with reflections derived from the actions carried out and ends with a third part with some conclusions, the result of the daily experience of an education inspector.

KEY WORDS: Educational inspection; actions; supervision; counseling; control; evaluation; educational system.

\section{Introducción}

$\int$ S Difícil ENTENDER la Inspección Educativa si no se conoce el día a día de la misma. Todo el mundo cree saber lo que es un inspector o inspectora de educación, sin embargo, cuando llegan al desempeño de la función muchos de los nuevos compañeros comentan que es increíble, que nunca pensaron todo lo que se hacía.

El análisis de la realidad del día a día se debe plasmar para que la comunidad vea cómo se va generando la historia. Además, a través de este análisis se genera un conocimiento que nos permite comprender el presente y forjar un futuro acorde a los tiempos, a los derechos de las personas, a los avances científicos y metodológicos y a un nuevo enfoque de la sociedad en relación a la educación.

Las historias de vida van construyendo el acervo profesional y, además, son una técnica de investigación cualitativa, dentro del método biográfico-narrativo, basada en el análisis del investigador y la transcripción que este realiza de su propia experiencia o de la que le transmiten otras personas (Rodríguez Gil y García, 1996). Para Ruiz Olabuélaga (2012), la historia de vida, en la investigación cualitativa, es un método de los más eficaces para conocer la interpretación que los individuos crean y relejan del mundo social que les rodea.

Por otra parte, las historias de vida nos permiten generar versiones diferentes o alternativas a la historia social o a la creencia popular a partir de la narración de experiencias personales que facilitan el conocimiento de la actuación en diferentes circunstancias, la relación que se establece con los diferentes colectivos implicados, con las instituciones y con sus imaginarios.

No es difícil encontrar en la literatura educativa historias de vida de profesores, lo que sí resulta extraño es encontrar alguna de algún inspector o inspectora en relación a su práctica diaria y, además, son poco conocidas. Podemos mencionar el testimonio de vida de M. ${ }^{a}$ Teresa López del Castillo con «La inspección que he vivido» (1993) en la que describe su trabajo y su visión de la enseñanza a través de los diferentes momentos históricos en los que ha ejercido. El compendio más amplio que recoge y cita a un gran número de inspectores y las aportaciones que estos han hecho a la Inspección de Educación a través de artículos, investigaciones, participación en 
congresos, etc., es el de Santiago Esteban Frades (2014) en La Inspección de Educación. Historia, pensamiento y vida, donde el autor, además, dedica un importante número de páginas a narrar en forma de diario cómo es el comienzo de curso de un inspector escolar; presenta la visión de la Inspección de Educación y de los centros educativos de una inspectora accidental a través de una entrevista, y cierra el libro con su propio testimonio personal.

La brevísima historia de vida que se presenta a continuación a través del relato analizado de tres días de una inspectora de educación, un día por trimestre, pretende traducir los hechos, símbolos, gestos y anécdotas cotidianas en palabras que permitan al lector conocer el trabajo de la Inspección de Educación y relacionar una historia personal cualquiera con la historia social.

\section{25 de septiembre de 2017 , un día cualquiera de principios de curso.}

Como cada mañana, llego a mi despacho de la Dirección Provincial.

Hoy es lunes, por lo tanto tengo reunión de distrito. En mi distrito somos 4 inspectores más el coordinador que es el que nos transmite los temas y asuntos fundamentales que tenemos que resolver esta semana.

El coordinador se ha reunido el viernes con el resto de coordinadores de los otros distritos de la provincia y con el inspector jefe. Es una estructura informativa en cascada en la que cada semana los coordinadores y el jefe toman decisiones que luego son transmitidas al resto de inspectores de la provincia. El guion de trabajo parte del Plan Anual de la Inspección, que se publica cada curso a través de una Resolución. Esta semana de comienzo de curso, por ejemplo, recibimos la siguiente información:

\subsection{En cuanto a información específica del área}

Tenemos ya disponible el Informe regional de la actuación prioritaria que desarrollamos el curso pasado y que consistió en realizar el «Asesoramiento y supervisión de la implantación, en los centros sostenidos con fondos públicos, de las modificaciones introducidas en el currículo, la organización, promoción y evaluaciones en los cursos de $2 .^{\circ}$ y $4 .^{\circ}$ de Eso y $2 .^{\circ}$ de Bachillerato».

Esta actuación, como todas las de corte pedagógico/normativo, ha sido muy enriquecedora tanto para los inspectores como para los centros, ya que ha permitido revisar la propuesta curricular y las programaciones didácticas en profundidad, completando el trabajo que se había hecho el curso anterior en I. ${ }^{\circ}$ y $3 .{ }^{\circ}$ de la Eso y en.$^{\circ}{ }^{\circ}$ de Bachillerato, y realizando, por tanto, el correspondiente análisis de cumplimiento de las competencias básicas o clave, el seguimiento coherente de los contenidos, de los criterios de evaluación, etc.

Nos dan la relación de materias optativas y de modalidad que los centros tienen autorizadas por debajo de la ratio, para este curso.

- El de este curso se ha publicado en la Resolución de 7 de septiembre de 2017, de la Dirección General de Política Educativa Escolar, por la que se establecen las directrices para la elaboración de los planes anuales de actividades de las áreas de Inspección Educativa de las direcciones provinciales de educación para el curso académico 2017/2018. 
Nos informan de que, a partir de ahora, los informes del área sobre los servicios complementarios en los centros concertados serán emitidos por un solo inspector después del análisis de los mismos por parte de una comisión. Los centros concertados tienen que solicitar una autorización y comunicar los precios de las actividades escolares complementarias, las actividades extraescolares y los servicios complementarios (comedor escolar, transporte escolar, el gabinete médico o psicopedagógico, el seguro escolar o cualquier otro de naturaleza análoga...). El objetivo de que se haya decidido que los informes sean emitidos por un solo inspector o inspectora es muy acertado pues así se evitan las diferencias de criterio y se homogeneiza la propuesta, evitando que unos centros sientan que se les han exigido más requisitos o controles que otros.

Esta actuación que realizamos conlleva un control que es necesario en la sociedad actual pues impide que centros sostenidos con fondos públicos se conviertan en más elitistas porque ofrecen unos servicios caros a los que solo podrían acceder unos pocos.

Desde el área de la Secretaría Técnica, en concreto desde la sección de Alumnos y Servicios Complementarios, se nos solicita que revisemos los títulos para que estos estén adaptados a la LOE modificada por LOMCE. Llevamos unos años padeciendo la rápida alternancia de las leyes de educación que nos obliga a los inspectores a ejercer el control y velar por el cumplimiento de la norma, evitando así posibles fraudes en las titulaciones ya que si esto ocurriera estas dejarían de tener valor.

Nos explican que, a partir de este curso, los escritos de los centros y/o miembros de la comunidad educativa que se reciban en esta Dirección Provincial vía Registro electrónico no serán impresos en papel para pasárselo al inspector que ha de dar respuesta a través del correspondiente informe, sino que nos los enviarán directamente, por el mismo formato electrónico, a cada inspector. Estas son las consecuencias de una Administración inmersa en un proceso de modernización que pretende facilitar los trámites a la ciudadanía y agilizar los plazos de respuesta al evitar la lentitud de pasar «papeles» de un despacho a otro, hasta que alcanzan su destino final.

No es raro que cada curso se haya abierto algún centro nuevo y ahora es el momento de asignárselo a un inspector. En nuestro distrito hay un centro nuevo de Formación Profesional de Técnico Deportivo de Grado Medio y el coordinador propone que lo lleve una inspectora que ya lleva otro centro de Formación Profesional y Régimen Especial pues así se rentabilizan los procesos que tenemos que realizar en función de los diferentes tipos de centros y enseñanzas y especialmente en este caso de las enseñanzas deportivas, que tienen sus peculiaridades específicas.

Los inspectores e inspectoras llevamos todo tipo de centros: desde las escuelas de Educación Infantil de cero a tres años, pasando por los centros de Educación Infantil y Primaria, los Institutos de Educación Secundaria, los centros de Formación Profesional, las escuelas de Música y los Conservatorios, los Centros Extranjeros, los Equipos de Orientación Educativa y Psicopedagógica, las aulas hospitalarias, los Centros de Formación e Innovación del Profesorado, las Escuelas de Arte, las Escuelas Oficiales de Idiomas, las Enseñanzas Deportivas, etc., hay que tener en cuenta que los centros educativos son el pilar básico de nuestro trabajo, son el alma mater de nuestro día a día, son el núcleo sobre el que gravita toda nuestra actuación tanto a nivel pedagógico, como organizativo. En los centros ejercemos muchas de nuestras funciones y atribuciones, desde la de control velando por el cumplimiento de la 
norma, hasta la de asesoramiento cuidando de potenciar nuevas metodologías, procesos innovadores, etc.

Esta diversidad de centros que atendemos ha generado históricamente un importante debate sobre si el inspector debe hacerse cargo de los centros en función de su especialidad, materia o nivel educativo de procedencia o no, es decir, si debe ser un inspector generalista y atender a todo tipo de centros. Desde mi experiencia de trabajo en un modelo interdisciplinar de inspector generalista, considero que esta es la manera más adecuada de abordar nuestra labor pues permite tener una visión global del sistema, de su problemática y, por tanto, de las soluciones o tendencias que abordar. Para que este modelo de inspector generalista sea eficaz, deben estar contemplados los tiempos necesarios de formación y los propios grupos de trabajo dentro de las áreas de inspección.

Debatimos sobre la exención de la materia de Educación Física y las convalidaciones entre las asignaturas de las enseñanzas profesionales de Música y Danza y las materias de la Educación Secundaria Obligatoria y el Bachillerato, pues es un tema que a principios de curso genera muchas dudas en los centros y hay que proceder a revisar la normativa para poder hacer las correspondientes aclaraciones.

En estos casos, nos encontramos con un colectivo de familias sensibles que demandan permanentemente información pues sus hijos suelen ser estudiantes brillantes que pueden simultanear los dos tipos de estudios; estas familias son, por lo general, muy exigentes y nos visitan con frecuencia preocupados no solo por las convalidaciones, sino también por los procesos de elección de optativas, por el tipo de centros más facilitadores en su tarea de conjugar ambas enseñanzas.

En cuanto a las actuaciones que tenemos que realizar, hoy comienzan las clases para el alumnado del primer curso de los ciclos formativos de grado superior de las enseñanzas profesionales de artes plásticas y diseño, los ciclos formativos de grado medio de las enseñanzas profesionales de artes plásticas y diseño, las enseñanzas en centros de personas adultas, por lo que tenemos que realizar un control de incidencias que puedan afectar al inicio de las actividades lectivas.

Finalmente, hacemos un repaso del calendario de las actuaciones, cuándo tenemos que tener listos los informes de las Memorias de los centros; las modificaciones del calendario escolar que no afecten al inicio del curso; la validación de los datos de los centros en relación a alumnos/grupos en los centros concertados de Educación Especial, ESO y Bachillerato; y, finalmente, la validación de los datos del alumnado que presenta necesidades específicas de apoyo educativo en todos los centros concertados ${ }^{2}$.

ALGR es una base de datos en la que los centros introducen el número de alumnos que tienen en cada grupo; ATDI es otra base de datos, en este caso de alta seguridad, en la que los centros introducen la relación del alumnado que presenta necesidades específicas de apoyo educativo, su diagnóstico, los apoyos que requieren, su historia escolar, etc. En ambos casos, los inspectores e inspectoras validamos electrónicamente los datos después de comprobar que son correctos. Es importante para la Administración

El calendario viene regulado con los plazos de recogida de datos mediante las aplicaciones informáticas en la Resolución de 29 de junio de 2017, de la Dirección General de Política Educativa Escolar, por la que se dispone la publicación de la Instrucción de 28 de junio de 2017, de la misma Dirección General, por la que unifican las actuaciones de los centros docentes que imparten enseñanzas no universitarias en Castilla y León correspondientes al inicio de curso escolar 2017/2018. 
tener datos a tiempo real y contrastados por una figura de autoridad, como somos los inspectores e inspectoras, para adjudicar los recursos con justicia, hacer estudios de viabilidad o de necesidades, tomar decisiones de planificación, etc.

Ya tenemos prácticamente terminados todos los informes de las Memorias que han presentado los centros al finalizar el curso pasado y con la mayoría de ellos ya las hemos analizado. En la memoria anual quedan recogidos los resultados y el desarrollo del curso, es una reflexión que aporta los datos cuantitativos y cualitativos que nos van a permitir a los inspectores analizar el desarrollo del curso académico y a los centros elaborar propuestas de mejora. Los directores se sorprenden cuando vas con su Memoria llena de anotaciones señalándoles algunos objetivos que no se han logrado, la eficacia de los proyectos que han realizado a lo largo del año o la viabilidad de las propuestas de mejora que plantean, entre otras muchas cosas, pues piensan que algunos de los documentos que realizan no se los lee nadie, por lo que agradecen, enormemente, el feedback que les damos.

Al terminar la reunión regreso a mi despacho y me encuentro con que ya me está esperando la directora de un Colegio Rural Agrupado (CRA) que es nueva este año y se siente muy agobiada pues no quería ser directora y tuve que proponerla en contra de su voluntad ya que, después de hacer una reunión con los miembros del claustro, era la única con posibilidades de dirigir el CRA. En este CRA vemos un ejemplo de uno de los problemas que padecen las escuelas rurales de cyL, la despoblación, pues solo le quedan dos localidades con alumnado suficiente como para mantener el aula abierta (la tercera aula deja de funcionar precisamente este curso pues se quedó con solo dos alumnos que ahora van en el transporte escolar a la localidad donde está la cabecera del CRA).

Otro problema en las escuelas rurales de en Castilla y León es la falta de estabilidad de la plantilla de profesorado que prefiere ir a centros urbanos y con jornada continuada en lugar de viajar diariamente a la zona rural y, especialmente, a los centros que tienen la jornada partida. La falta de estabilidad hace inviable el desarrollo de un Proyecto Educativo a medio o largo plazo y el profesorado, que va a estar un año, asume el currículo asépticamente, sin más innovación o adaptación al medio perdiéndose así la posibilidad de innovar y experimentar en condiciones muy óptimas por tener muy bajas las ratios. La escuela rural está pasando por uno de sus peores momentos debido al problema de la despoblación. Desde la Inspección de Educación asistimos, año tras año, al cierre de escuelas por falta de alumnado, a pesar de los esfuerzos de la Consejería de Educación, que mantiene escuelas rurales con tan solo cuatro alumnos ${ }^{3}$.

Para hacer la propuesta de director o directora del CRA, me tuve que reunir con todo el claustro formado por dos profesoras definitivas y 4 provisionales e interinas. Una de las profesoras definitivas está de baja maternal y piensa ampliar la misma (en el centro estaban esperando a su sustituta). La reunión fue desoladora pues pude comprobar la falta de implicación del profesorado que se sentía de paso, ninguno tenía interés en formar parte del equipo directivo, al final propuse para el nombramiento a la otra profesora definitiva en la que descubrí, a pesar de su enorme timidez, un gran amor por la escuela, una importante implicación con el pueblo y ganas de hacer bien las cosas y de mejorar el CRA y de modernizarlo. El problema que más asusta a esta profesora es que no maneja las TIC y como el centro es tan pequeño no puede tener ni jefatura de estudios ni secretaría para suplir este hándicap.

En el curso 2018/19, se mantienen escuelas rurales con tres alumnos. 
Es una situación difícil la de encontrar profesorado voluntario que se presente por proyecto a la dirección de los centros rurales, la situación es la misma que la descrita para el profesorado, con el agravante de que los directores y directoras tienen más responsabilidad, asumen más problemas y, generalmente, les falta tiempo para tener todo al día. Si lo unimos a lo poco reconocido y mal pagado que está el cargo, nos encontramos con la dificultad de encontrar a candidatos adecuados.

Los temas por los que viene hoy tan agobiada esta directora son los siguientes: primero, para consultarme cómo actuar con una de las profesoras interinas que está llegando tarde a clase todos los días, ya ha sido advertida por la directora y le ha contestado «que se pierde por estas carreteras rurales»; esta profesora también se ha ido al médico varios días a media mañana o a casa pues dice «que se encuentra mal» $\mathrm{y}$, además, se queja de un alumno de $6 .^{\circ}$ que tiene problemas de conducta, al que echa de clase y con el que se enfrenta como de igual a igual. El segundo tema que me cuenta la directora es que ha descubierto que alguien del pueblo ha metido los caballos en el patio durante el fin de semana y no han limpiado los excrementos. Y, finalmente, manifiesta que le está costando mucho elaborar el DOC $^{4}$ pues no controla el programa informático con el que se hace.

Intento calmarla y darle respuestas útiles que le ayuden a resolver los problemas que son solo el fruto de su inexperiencia como directora:

En relación al tema de la profesora interina, le comunico que iré en estos días al centro para hablar con ella y recordarle sus funciones como docente recogidas en la LOE/LOMCE, la importancia del cumplimiento del deber y del horario y las posibilidades de acudir al médico fuera de las horas lectivas y advertirle que si estas conductas se mantienen podría estar incurriendo en faltas que están tipificadas en las normass.

El mismo día que vaya al centro, nos reuniremos la directora y yo con la orientadora y con esta profesora para ver qué ocurre en la relación entre el alumno de $6 .^{\circ}$ y la citada profesora y establecer las pautas de conducta que ella debe adoptar para tratar con dicho alumno y que el resto de profesores maneja ya que el chico solo manifiesta las conductas disruptivas con esta profesora. Aparentemente, lo que subyace en este caso es algo conocido, aunque afortunadamente no vemos con demasiada frecuencia: es un profesor que no está contento en su trabajo, está desmotivado o quizá quemado por los años de interinidad que no le permiten asentarse en ningún sitio, ni comprometerse con las familias ni con los proyectos del centro, un profesor que nunca elige su curso sino que siempre le toca el que no quieren los demás, el último que llega y no elige su material, sus libros, su programación, etc., es, año tras año y centro tras centro el «último mono».

El incidente de los caballos es el típico caso que los directores con experiencia resuelven solos, pero a veces tenemos que intervenir en cosas tan básicas como decir a la directora que debe llamar al Ayuntamiento para que realicen inmediatamente la limpieza del patio y avise al dueño de los caballos de que no puede volver a meterlos en el centro. Mientras tanto, los niños pueden disfrutar del recreo en otras dependencias

4 Documento Orgánico de Centro que se hace anualmente y en el que constan todos los datos del centro, la composición de los diferentes órganos del centro, las enseñanzas que se imparten, los horarios del alumnado y del profesorado, los servicios complementarios, el inventario, etc.

Ley $7 / 2005$, de 24 de mayo, de la Función Pública de Castilla y León, en el Real Decreto Legislativo 5/20I5, de 30 de octubre, por el que se aprueba el texto refundido de la Ley del Estatuto Básico del Empleado Público y en la Ley 40/2015, de I de octubre, de Régimen Jurídico del Sector Público. 
del centro, por ejemplo, el gimnasio. Afortunadamente, este centro es muy grande pues, en sus tiempos, llegó a ser cabecera de comarca y tenía una escuela comarcal con mucha matrícula.

En relación al Doc, la tranquilizo y le digo que tiene tiempo pues ya entregó los horarios del profesorado y de los alumnos antes del is de septiembre, ahora para entregar la Programación General Anual (PGA) que contiene el Documento de Organización del Centro (DOC) tiene de plazo hasta mediados de octubre. Le sugiero que busque entre el profesorado a algún compañero que le pueda echar una mano con las TIC para hacer el DOC y mantener el resto de aplicaciones informáticas con las que trabajamos: ALGR, ATDI, Convivencia, etc.

Cuando la directora se marcha, abro el correo electrónico y reviso las nuevas publicaciones del $B O C y L$, algunas consultas de mis centros y el correo de un padre que ya conozco del año pasado y que se queja pues los apoyos de PT y AL que su hijo necesita se los han organizado fuera del grupo clase y en horas de lengua, en lugar de en las horas de inglés que es lo que él solicitó.

Intervengo en este caso desde el curso pasado en el que la familia pidió que el niño de primero de primaria no acudiera a las clases de la sección bilingüe y le dieran las ciencias y la educación física en castellano, pues al parecer padece un Trastorno Específico del Lenguaje (TEL) y no se entera de nada en inglés. El centro tiene línea tres y todas ellas son bilingües. El profesorado piensa que al niño no le pasa nada, no están de acuerdo con los informes de médicos privados que le diagnostican un TEL y el estudio que le ha hecho la psicopedagoga del Equipo de Orientación del Sector no aporta un diagnóstico de TEL. El centro considera que el niño está muy presionado por los padres para que obtenga buenos resultados, pero que es muy pequeño aún e irá progresando poco a poco, por lo que es absurdo que no acuda a las clases bilingües que son lúdicas y el alumno está feliz y perfectamente integrado.

Ante tal discrepancia decidí entrar un rato en su clase en inglés y descubrí que, efectivamente, el niño se lo pasa muy bien pero lo único que hace es imitar al resto de los niños y cuando le das a él directamente alguna instrucción, no comprende ni lo más elemental. La visita al aula es una práctica no demasiado habitual por parte de los inspectores, que solemos circunscribirla a las situaciones de denuncias contra la actuación de algún profesor; también la empleamos para los procesos de evaluación del profesorado, que deberían ser bastante más habituales de lo que son pues con ellas desarrollamos los inspectores un rol pedagógico que suele resultar muy bien valorado por el profesorado ya que les aportamos una visión comparativa y amplia de las muchas experiencias que vemos en el día a día.

Este es uno de los casos típicos con los que nos encontramos con dos posturas y ninguna de ellas tiene la razón completa: por una parte, unos padres angustiados, que no creen en las bondades del sistema educativo si este no funciona como ellos consideran, y solo se fijan en la evolución de los aprendizajes de su hijo, aprendizajes de contenidos y no adquisición de competencias y, por otra, unos profesores y equipo directivo con un planteamiento educativo diferente que no consideran que el alumno necesite una intervención educativa diferente. La labor de mediación del inspector en este caso es fundamental para mantener un equilibrio entre el centro y la familia, aunque esto no siempre es posible y las familias optan por el cambio de centro.

Antes de irme a casa, recibo a una familia cuyo hijo suspendió las FCT de un Ciclo Formativo de Grado Superior de Deporte pues estuvo enfermo, que me piden que 
cambie al chico el lugar de las prácticas pues la empresa se portó fatal con él por faltar a las prácticas. Les remito al responsable de las FCT de su centro y les indico que la norma no impide hacer dicho cambio.

Este centro es concertado y solo imparte ciclos de FP. Siempre tengo mucho trabajo pues cambian a bastantes profesores cada año lo que me obliga a revisar si la titulación de los nuevos es la adecuada y para algunos ciclos es realmente difícil encontrar perfiles adecuados a la norma y que además tengan el Máster de Secundaria o el antiguo CAP, es el caso de los enfermeros, los técnicos de radiodiagnóstico, los ingenieros de telecomunicaciones o los técnicos de hípica, entre otros, ya que el mercado laboral tiene una amplia oferta para ellos, más interesante que la docencia pues les brinda contratos de más horas y mejor pagados. Los pocos especialistas que se encuentran no suelen tener el Máster de Secundaria pues nunca pensaron en hacerse profesores.

\section{Io de febrero de 2018, un día cualquiera del segundo trimestre}

$\mathrm{Al}$ abrir el correo electrónico, que es lo primero que hago cada mañana, para responder a mis centros, ver si hay novedades en el $B O C y L$ y resolver los escritos que nos llegan por el registro electrónico, me encuentro con que el inspector jefe nos pide que informemos a nuestros centros sobre el «Protocolo de actuación en agresiones al personal docente y no docente de los centros sostenidos con fondos públicos» ${ }^{6}$, pues aunque la norma se ha publicado hace poco más de un mes, parece que hay centros que no lo tienen claro, por lo que tenemos que informarles de que el protocolo contempla las actuaciones que tienen que llevar a cabo los centros, la Dirección Provincial de Educación y la Inspección Educativa e informarles sobre la solicitud de asistencia jurídica por parte del profesorado.

El tema de las agresiones al personal docente y no docente en los centros educativos, tan en el boca a boca de la sociedad, seguramente influenciada por la publicidad que se hace cuando se produce algún caso, afortunadamente, no es muy frecuente, pero sí es tremendamente distorsionador de la vida de un claustro. Al volver de las vacaciones de Navidad, en un centro de infantil y primaria mío de la ciudad, una madre le dio una bofetada al director pues, según ella, a su hija no le hacían caso, se reían de ella y la culpa era del director "por no poner orden en el centro». Al margen del lío que se preparó pues era el momento de la entrada de la mañana, con padres y madres, alumnado, profesorado, la llamada a la policía y la posterior publicación en los periódicos locales y nacionales, las llamadas de la radio y de la televisión, etc., lo más difícil en estos casos, desde mi punto de vista, es restablecer la calma entre el profesorado, que se altera muchísimo y que, antes, sucesos como este, totalmente reprobables, saca a colación todos los tópicos desafortunados del ideario negativo profesional actual: «no nos respetan», «los padres hacen lo que quieren y nosotros no tenemos ningún derecho»... . En estos casos, el trabajo de un inspector es muy delicado pues hay que evitar el tremendismo fruto de la indignación y reconducir al colectivo de educadores

Orden EDU/IO7072017, de I de diciembre, por la que se establece el «Protocolo de actuación en agresiones al personal docente y no docente de los centros sostenidos con fondos públicos que imparten enseñanzas no universitarias en la Comunidad de Castilla y León».

7 El juicio contra la madre se ha saldado con una sentencia que la condena a pagar una multa de so euros. 
hacia el sentido común. Como servidores públicos, estamos expuestos a los desaires de personas que viven alteradas, sin educación y sin medida. Son momentos donde lo curricular queda en segundo plano y hay que recurrir a las competencias sobre civismo. Nuestra labor, en estos casos, es la de influenciar sobre el sistema relacional de la organización escolar que funciona como una microsociedad que ha sufrido un importante revés, pero que se debe resituar en la consecución de sus objetivos y de su Proyecto Educativo.

Algo más habitual son las denuncias por acoso entre alumnos. En todas las Comunidades Autónomas ${ }^{8}$ se han establecido Protocolos de Actuación para los supuestos de posible acoso en centros docentes. La legislación al respecto empezó por establecer las normas de convivencia y disciplina en los centros educativos movidos por la especial preocupación que se detectaba en la comunidad educativa y en la sociedad en general, la existencia de conflictos en el ámbito escolar y la exigencia de una respuesta adecuada por parte de los poderes públicos. Los Reglamentos de Régimen Interior de los centros empezaron a recoger procedimientos de actuación ante situaciones de conflicto y, en el marco de su autonomía, a elaborar sus propias normas de convivencia y conducta, de obligado cumplimiento, concretando, además, procedimientos y medidas para la prevención y la resolución de los conflictos.

Todos somos conscientes de que los sucesos puntuales son muy mediáticos, se agravan con el uso de las redes sociales y el ciberacoso y producen un fuerte impacto social. Pero los mensajes de «tolerancia cero», unidos a las nuevas medidas de intervención, deberían estar ayudando a lograr una convivencia adecuada en los centros educativos. Sin embargo, no podemos olvidar que los inspectores, además de las funciones que nos asigna la normativa en este tema, debemos tener especial sensibilidad a promover en los centros medidas preventivas tales como la sensibilización y la implicación de todos y cada uno de los sectores de la comunidad educativa, incluido el alumnado. Tampoco podemos olvidar que, en general, la convivencia escolar es buena, como demuestran los datos recogidos en la aplicación informática $\mathrm{CON}^{10}$.

Hoy es lunes, por lo tanto tengo que dejar hecha mi programación semanal en la base de datos GINS ${ }^{\mathrm{II}}$, sobre la que después, una vez realizada la actuación, añadimos el informe o la hoja de visita y a través de la cual tanto en la jefatura de inspección como en la inspección central pueden hacer un seguimiento de nuestro trabajo y hacer análisis estadísticos de los tiempos que nos llevan las diferentes tareas, el grado de incidencia de cada una de ellas, etc. Claro que esto es en teoría, pues llevamos años poniendo de manifiesto las deficiencias que esta base de datos contempla ya que, por ejemplo, cuando visitas un centro en GINS solo podemos registrar una actuación, cuando, en

8 Por ejemplo, en Castilla y León, la reciente Orden EDU/IO7I/20I7, de I de diciembre, por la que se establece el «Protocolo específico de actuación en supuestos de posible acoso en centros docentes, sostenidos con fondos públicos que impartan enseñanzas no universitarias de la Comunidad de Castilla y León» y la Orden EDU/1921/2007, de 27 de noviembre, por la que se establecen medidas y actuaciones para la promoción y mejora de la convivencia en los centros educativos de Castilla y León.

9 Existen programas específicos al respecto, como, por ejemplo: Par (Parar el acoso, Apoyar a la víctima y Reeducar al agresor) en el marco del «Plan antiacoso y por el buen trato» de la Consejería de Educación de la Junta de Castilla y León.

ro Es una aplicación informática donde los centros introducen los datos relativos a los incidentes de convivencia en su centro.

II Sistema de gestión de las actuaciones de la Inspección Educativa a través de la aplicación informática Gestión de Actuaciones de la Inspección Educativa de Castilla y León (GINs). 
realidad, generalmente acudes con más asuntos que quedan reflejados en la hoja de visita; en GINs tampoco podemos recoger la cantidad de actuaciones que se hacen desde el despacho y que ocupan un porcentaje enorme de nuestro desempeño profesional.

En mi programación semanal, hoy tengo salida para visitar el instituto más emblemático de la ciudad, es el más antiguo, tiene más de mil alumnos y todo tipo de enseñanzas: Eso, bachilleratos diurnos y nocturnos de tres años y ciclos formativos de grado medio y superior diurnos y nocturnos y también a distancia. Es un centro al que cada vez que voy tengo que dedicarle tiempo pues el número de incidencias, dudas, problemas o casuística que se produce en él es considerablemente alto. En estos centros, tenemos que tener claro nuestro rol de asesoramiento legal y pedagógico que nos es demandado en cada visita.

Me voy al instituto pues están metidos dentro de la actuación prioritaria «Asesoramiento y orientación para el desarrollo de acciones contextualizadas en los centros que permitan la mejora de los resultados académicos y la prevención del abandono escolar temprano en las diferentes enseñanzas y niveles del sistema educativo», con la que se pretende analizar los resultados de los centros educativos con la finalidad de identificar los elementos comunes que pueden determinar los resultados académicos o el abandono escolar temprano. Este centro ha sido seleccionado contando con un estudio de los resultados pertenecientes a centros públicos y privados, en el que se indicaban las tasas netas de titulación en Eso y la diferencia respecto a la media provincial y regional. Es una actuación para $4 .^{\circ}$ de ESO y la estamos realizando durante el segundo trimestre y continuaremos en el tercero, teniendo en cuenta los resultados de la r. a evaluación y de la evaluación final del curso.

Hoy pretendo, en mi visita, reunirme con el equipo directivo para presentarles la actuación y realizar el primer análisis de los datos: ver el significativo incremento de alumnado con materias suspensas que han tenido estos dos últimos cursos, la disminución significativa en los resultados del centro, tanto de forma global como en algunas materias en concreto, etc. Además, les pediré algunos documentos de interés, como el proyecto de autonomía, los planes de mejora, las programaciones, las actas de las juntas de evaluación y el plan de formación para ir estudiándolos. También les voy a explicar que se va a recoger información, a través de cuestionarios, a los miembros del equipo directivo y profesorado, para conocer su valoración sobre aspectos clave que pueden incidir en los resultados escolares. Y les voy a comunicar que el equipo directivo y la CCP, después de recibir los resultados de dichos cuestionarios, tendrán ya que elaborar un informe con su valoración de los resultados obtenidos, indicando las causas que pueden justificar los resultados; finalmente, determinaremos las medidas de actuación a implantar durante la tercera evaluación.

El tema les resulta muy interesante e informarán a todo el claustro de que tendremos reuniones con el profesorado para analizar los resultados y recabar su análisis y valoración; se analizarán las programaciones y el cumplimiento de las mismas, al menos en los casos de las materias cuyas calificaciones hayan podido contribuir a la obtención de medias bajas en el centro y se supervisarán las memorias correspondientes; la valoración que en la misma se realiza tanto del cumplimiento de las programaciones como de los resultados y si es necesario asistiré a las sesiones de evaluación final. Además, estoy segura de que el equipo directivo se va a implicar con interés tanto en el análisis de los resultados y de las variables que inciden en el fracaso escolar en su centro como en la elaboración de medidas útiles que les permitan ir alcanzando cotas mejores. 
Nada más llegar al instituto el director me plantea que un alumno de $3 .^{\circ}$ de la Eso quiere cambiarse a enseñanzas a distancia pues, según dice la madre, tiene narcolepsia y no puede seguir las clases ordinarias pues se duerme, no pude permanecer despierto toda una sesión de clase. Les explico cómo es el proceso para la incorporación de un alumno de enseñanza obligatoria a enseñanzas a distancia, que lleva la Subdirección General de Aprendizaje a lo Largo de la Vida y Educación a Distancia y dentro de esta el Centro Integrado de Enseñanzas Regladas a Distancia (CIDEAD). Como la escolarización en Educación Secundaria corresponde en exclusiva a las cc. AA., el CIDEAD nos pedirá un informe a la Administración Educativa que tiene un doble objetivo, por un lado, que conozcamos la escolarización de todos los alumnos de nuestro ámbito territorial, especialmente la de aquellos alumnos que se encuentran en periodo de escolaridad obligatoria y, por otro, respetar las competencias exclusivas en materia de escolarización que los respectivos estatutos de autonomía atribuyen a las CC. AA. El CIDEAD escolariza dentro del territorio nacional con carácter excepcional a los deportistas de élite; al alumnado de conservatorios de danza y música que no pueden compaginar los estudios en un centro ordinario; al alumnado de familias itinerantes o a alumnos que tienen graves problemas para asistir a centros de manera presencial pues padecen situaciones, por ejemplo, de agorafobia, acoso escolar y otros que se valoran desde la inspección y proponen a las administraciones educativas.

Cuando regreso a mi despacho en la Dirección Provincial me encuentro con un padre que acaba de llegar a visitarme. Aunque tenemos un día de guardia a la semana para atender a todo el mundo, siempre hay visitas inesperadas que vienen a vernos pensando que solo trabajamos en el despacho. En este caso, es un padre que quiere hacer una denuncia verbal pues su niña de 8 años y $2 .^{\circ}$ de Educación Primaria tiene que ir disfrazada a la fiesta de carnaval del colegio de Manneken Pis; dice que los niños se han reído de ella y que la niña no quiere ir a la fiesta; me explica que cada niño va disfrazado de un monumento europeo y que él quiere que la tutora se lo cambie por el de Torre Eiffel. Intento convencerle de que a priori todo parece una mera cuestión de género sin importancia, que es positivo para los niños acostumbrarse a romper ciertos estereotipos sexistas, que si es una cuestión de pudor puede disfrazarse de Manneken Pis vestido ya que en Bruselas lo visten muy a menudo y que le diré a la tutora que hable con la niña para ver cómo lo vive ella y si es necesario hacer ese cambio. No se va nada convencido pues él ve que lo fácil es cambiarle el disfraz y yo le digo que la fiesta de carnaval tiene un componente educativo para el aprendizaje de manera lúdica y que hablaré con la tutora para analizar el caso completo y que ella le llamará para explicarle la conclusión a la que lleguemos.

A continuación, llamo a la tutora que me explica que el disfraz de los monumentos europeos responde a la práctica de la unidad didáctica que están trabajando y que los niños decidieron, por sorteo, disfrazarse del monumento que les tocara. En relación a esta alumna, señala que estaba encantada de disfrazarse de Manneken Pis y que a toda la clase le resultó muy divertido, pero que no se rieron de ella. Decidimos que era más adecuado no aceptar el capricho del padre que es el que tiene prejuicios al respecto y así se lo hará saber la tutora hablando con él. (Desafortunadamente, el día de la fiesta de carnaval, la niña no acudió al centro). 
Tengo pendientes unas cuantas tareas de tipo burocrático que, en ocasiones, nos desbordan, voy a organizarlas priorizándolas por orden de urgencia e intentar mañana resolverlas todas. Son tareas como, por ejemplo: informar sobre la necesidad de cubrir la baja de un profesor con carácter de urgencia ya que está solo en una localidad de un CRA y, aunque de momento lo están sustituyendo los profesores itinerantes del CRA, debe cubrirse su baja inmediatamente por lo que no puedo esperar a mañana, haré ahora una comunicación ${ }^{12}$ que es un documento más breve y rápido de tramitar; tengo pendiente revisar la titulación de una profesora que quiere contratar un centro concertado que ha tenido una baja, para ello me remite la titulación académica y el certificado de haber cursado el Máster de Profesorado de Enseñanza Secundaria, pero le tengo que solicitar que me diga qué asignaturas va a impartir y que me mande la certificación académica para que pueda comprobar que dicha profesora ha cursado 24 créditos de formación de las asignaturas que vaya a impartir: también tengo un recurso de alzada de unos padres a los que se les ha denegado la beca de apoyo pedagógico ${ }^{13}$ del Ministerio de Educación y Formación Profesional; y, finalmente, también tengo la reclamación de los padres de un centro sobre la modificación de una parada del transporte escolar, en este caso, tendré que ir mañana al centro para ver el problema con el director.

Esta tarde he vuelto al trabajo, había quedado con la Comisión de Coordinación Pedagógica de un centro de la ciudad que está intentando introducir, en el día a día del aula, el trabajo por competencias. Ya las tienen escritas, a nivel teórico en la programación didáctica, pero me pidieron que me reuniera con ellos pues tenían muchas dudas en torno al trabajo por proyectos que estaban desarrollando y a la evaluación de las competencias.

La reunión es un verdadero placer pues se desarrolla a modo de debate ya que el profesorado plantea dudas que a su vez responde justificando cómo lo están haciendo y que nos está permitiendo ver cómo se acercan, a través de estas metodologías más innovadoras, participativas y motivadoras, al cumplimiento del principio de atención a la diversidad que vienen proclamando todas las leyes educativas desde la LODE en 1985. Esta reunión está sirviendo de acicate para los más reticentes pues el hecho de que una inspectora les esté apoyando, asesorando y animando en estos procesos de cambio e innovación les da seguridad. En estos casos, nuestra visión pedagógica de la innovación educativa ayuda a los centros que se embarcan en experiencias diferentes a seguir adelante, pues les ofrecemos la garantía de que la Administración les respalda y entiende su finalidad, el por qué y el cómo de la innovación. La Inspección, en estos centros, siempre está alerta para que no se den procesos de cambio que produzcan, por ejemplo, el refuerzo de la desigualdad social; debemos también estar atentos a no confundir innovación con cuestiones anecdóticas y plantear en los centros que esta supone modificar aspectos esenciales del sistema educativo e implicar a todos los docentes, alumnos y familias, poniendo sobre la mesa algunos de los principales problemas que afectan a nuestro sistema educativo, tales como la falta de equidad, la segregación escolar, la falta de motivación de nuestros estudiantes, etc. Ojalá pudiéramos ejercer más a menudo esta tarea.

12 El Decreto 92/2004, de 29 de julio, por el que se regula la Inspección Educativa en Castilla y León, recoge los instrumentos de la Inspección: Informes, Actas y Comunicaciones.

${ }^{13}$ Todos los años se convocan, a través de una Resolución que sale a principios de curso, las ayudas para alumnos con necesidad específica de apoyo educativo. 


\section{Is de junio de 2018, un día cualquiera de finales de curso}

Ya estamos metidos en el final del curso. En este mes, el trabajo del día a día es muy duro pues nos vemos envueltos en una dinámica tremenda con los procesos de escolarización del alumnado para el próximo curso, la organización de las plantillas y de los cupos del profesorado, la previsión de nuevos directores en los centros en los que se nos han marchado por traslado, las reclamaciones de notas, etc. Además, tenemos muchas visitas de padres derivadas de los resultados de la evaluación.

Hoy me encuentro en mi buzón la petición de la directora provincial de Educación para que responda a las alegaciones que ha presentado una profesora de uno de mis institutos en relación a una propuesta de apercibimiento y retención de los haberes correspondientes que se le ha hecho como consecuencia de que se ha ausentado del instituto en tres ocasiones en las sesiones de evaluación del alumnado y sin ningún motivo justificado. En sus alegaciones dice que son falsas todas las acusaciones por lo que la situación me obliga a ir al centro, que está en la zona rural, para entrevistarme con el director y la jefa de estudios. Todos se ratifican con lo que ya señalaron en su día.

Es curioso que, con lo claras que aparecen en la LOMCE las funciones del profesorado, que señalan, entre otras, "la evaluación del proceso de aprendizaje del alumnado, así como la evaluación de los procesos de enseñanza» es del profesorado, así como «la coordinación de las actividades docentes, de gestión y de dirección que les sean encomendadas» $\mathrm{y}$ «la participación en la actividad general del centro», esta profesora no las haya respetado sin motivo alguno.

En base a todo esto, tendré que volver a hacer un informe para proponer de nuevo un apercibimiento y la correspondiente retención de los haberes correspondientes teniendo en cuenta la Ley 7/2005, del 24 de mayo, de la Función Pública de Castilla y León, que indica que «al manifestar negligencia y descuido en el cumplimiento de sus funciones» e «incumplimiento de la jornada y el horario sin causa justificada», se considera que esta profesora ha podido cometer una falta leve. Esta es una de las situaciones más desagradables con las que nos encontramos en nuestro trabajo, cuando hay que proponer sanciones al profesorado. Afortunadamente, estas actuaciones son mínimas ya que contamos con una gran mayoría de profesores comprometidos, cumplidores y verdaderos profesionales de la educación.

No he podido terminar el informe cuando aparece la madre de una alumna de $4 .^{\circ}$ de Educación Secundaria Obligatoria con la que ya había hablado en el mes de enero pues tenía quejas del trato recibido por su hija tras su incorporación a las clases una vez acabado un intercambio escolar en Francia en el primer trimestre. Al parecer, los padres se negaron a que su hija hiciera en España los exámenes de las asignaturas del primer trimestre pues decían que en el instituto le pusieran las notas que aportaban del liceo francés. En ese momento lo solucionamos hablando con el jefe de estudios para que este a su vez hablara con todo el profesorado y analizaran qué dificultades les impedían convalidar esas notas, especialmente teniendo en cuenta que el nivel curricular de la alumna es elevado y que podían hacer el seguimiento en el segundo y tercer trimestre. Ningún profesor puso objeciones al respecto, al parecer el problema fue de tipo burocrático pues el convenio del intercambio escolar era de tipo privado y no habían recibido ninguna comunicación oficial más que el boletín de notas francés cuando la niña se incorporó en enero y la explicación telefónica de los padres cuando 
les llamaron porque la alumna no estaba acudiendo al instituto. Ahora la madre me comunica que va a matricular a su hija en otro instituto que tenga Bachibac ${ }^{14}$ para continuar con los estudios de francés.

No es una buena política la de los padres que no comunican en los centros decisiones importantes que afectan a la escolaridad de los hijos pues genera una mala sensación entre el profesorado, que se sienten ninguneados; además, se pierde la relación de confianza mutua entre la familia y el centro, aspecto que las investigaciones al respecto señalan que es fundamental para impulsar la vida académica de los estudiantes, favorecer la motivación, especialmente, en la Educación Secundaria, aumentar la autoestima del alumnado, evitar situaciones de acoso, etc., sin olvidarnos de que la colaboración familia/escuela es un derecho y un deber recogido en las leyes educativas y en la Constitución.

Recibo la llamada del director de un centro público de Educación Infantil y Primaria sobre un tema del que ya ayer una profesora me preguntó «si tiene obligación de asistir a la actividad complementaria que tiene que realizar con sus alumnos de $3 .^{\circ}$ de Educación Infantil»; le respondí que sí y le recuerdo el artículo de la LOMCE que señala, entre las funciones del profesorado, la de «la promoción, organización y participación en las actividades complementarias, dentro o fuera del recinto educativo, programadas por los centros». Ella insiste en que no tiene por qué ir a la actividad complementaria pues, a principio de curso, «manifestó que no quería» hacer salidas, que su presencia no es necesaria pues van suficientes padres y, además, porque «le han dicho en el sindicato que, según el artículo 45 de la Orden de 29 de junio de 1994 por la que se aprueban las instrucciones que regulan la organización y el funcionamiento de las escuelas de educación infantil y de los colegios de primaria, no tiene por qué ir». Le digo que es una actividad complementaria aprobada en la Programación General Anual (PGA) y que debe cumplir las órdenes del director que es el que organiza el centro, por tanto, que cumpla con lo que el director le ordene pues es su superior jerárquico y que después de ir a la actividad complementaria organizada para el día siguiente, haga un escrito alegando su disconformidad.

El director del centro me comunica que, a pesar de todo lo que le expliqué ayer, esta profesora le ha pedido por escrito la orden de salir a la actividad complementaria $y$, aunque se lo ha dado por escrito, lo que era innecesario pues es una de sus funciones, ella no ha salido con los niños.

Ahora soy yo la que llamo a la profesora para preguntarle por qué no ha salido a la actividad complementaria, por qué no ha acatado las órdenes del director y por qué ha hecho caso omiso a las recomendaciones que le di al respecto, a lo que me responde que «gracias por el asesoramiento, pero que ya le explicaron los sindicatos lo que tenía que hacer». Antes de colgar el teléfono le recuerdo que los incumplimientos acaecidos son faltas graves y pueden ser motivo para realizar una propuesta de expediente disciplinario si no existen causas que aconsejen lo contrario.

En este caso se nos mezclan varias cuestiones con las que nos solemos encontrar, una información mal dada, el incumplimiento legislativo y la confusión de una profesora que se considera con la razón suficiente como para saltarse todas las recomendaciones y órdenes que se le han dado. Podemos decir que, en general, los sindicatos

${ }^{14}$ Programa que permite al alumnado la posibilidad de alcanzar simultáneamente dos títulos nacionales: el de Bachiller y el Baccalauréat, abriendo así a los poseedores de esta doble titulación el derecho a acceder a la enseñanza superior española y a la enseñanza superior francesa. 
(que son en este caso los que han informado mal a la profesora) hacen una buena labor $y$, cuando dudan de cuestiones normativas que les plantean sus afiliados, recurren a nosotros antes de dar una respuesta equivocada. Lo que sí es un verdadero problema para todos es el maremágnum legislativo en el que llevamos inmersos los últimos años, donde conviven órdenes que avalan reglamentos orgánicos de centros que tienen obsoletos muchos de sus apartados, al menos, en esta Comunidad Autónoma. Y, finalmente, la confusión de la profesora que olvida las cuestiones jerárquicas en relación al equipo directivo y la función de control y supervisión que la Inspección Educativa tiene asignada por Decreto, considerando solo la atribución de asesoramiento.

Hoy estoy de guardia; todos los inspectores tenemos asignado un día en el que no podemos salir y así garantizamos que, en cada distrito, hay al menos un inspector disponible para dar respuesta a cualquier suceso, llamada o visita no programada en que la comunidad educativa nos pudiera requerir.

Voy a intentar resolver el tema que tengo pendiente de la revisión de un expediente sancionador ${ }^{15}$ que ha instruido un instituto a un alumno diagnosticado de TDAH ${ }^{16}$ y que ha sido recurrido por la familia a través de un recurso de alzada que señala que «los hechos que le imputan a su hijo no fueron así, que se vulneran sus derechos pues le han tomado declaración sin estar presentes los padres, que el instructor no ha sido imparcial y que no se ha tenido en cuenta su situación personal de TDAH» y, como consecuencia, solicitan que sea anulado el expediente disciplinario.

Tengo que organizar los pasos que voy a seguir en el instituto para hacer el informe a través del cual se dé respuesta al recurso de alzada: revisaré todo el procedimiento seguido por el centro para comprobar que se han cumplido los requisitos y los plazos y que el instructor nombrado reunía las exigencias que señala la norma y se le comunicó a los padres en tiempo y forma, sin que fuera recusado por ellos; comprobaré si en algún momento del proceso ha habido presentación de alegaciones o de pruebas por parte de los padres. Investigaré por qué le han tomado declaración sin estar presentes sus padres y analizaré su informe psicopedagógico, además de hablar con la orientadora para analizar si las conductas del chico son controladas o no y conocer si el alumno es consciente de todo lo que hace, ya que, como señala el Decreto 5I/2007 de derechos y deberes, hay que tener en cuenta las circunstancias personales que puedan haber incidido en la aparición de la conducta perturbadora, por tanto, si son motivo suficiente para anular el expediente.

En este caso, al margen del proceso legal, hay dos temas que generan controversia, uno es el que las familias, hartas y resabiadas de las quejas que les comunican los centros por las conductas disruptivas de sus hijos, sabotean las comunicaciones de los centros, para dilatar los procesos, al no darse por enteradas de las mismas, como es en este caso de expediente disciplinario; y otras es la duda que siempre genera la oportunidad o no de realizar un expediente disciplinario a un alumno que presenta discapacidad intelectual, trastornos de conducta, TDAH, trastorno mental, etc.

is El origen del expediente es en clase, cuando el profesor fue interrumpido por el móvil del alumno al que pidió, hasta en tres ocasiones, que dejara del utilizar el teléfono; el alumno hizo caso omiso y el profesor se acercó a él para pedírselo a lo que el alumno «reaccionó violentamente diciendo que no le tocara y profiriendo insultos y amenazas».

${ }_{16}$ Trastorno por déficit de atención e hiperactividad. 


\section{Conclusiones}

A través de las historias de vida, el papel de la Inspección de Educación es muy complejo y variado, es fácil que en un solo día ejerza tareas de control, evaluación y supervisión; de asesoramiento pedagógico, curricular, legal o administrativo; de coach, etc.

A lo largo del tiempo, he podido constatar que la sola presencia del inspector/a, en muchas ocasiones, es fundamental para tranquilizar a los equipos directivos, al profesorado y a las familias que cuentan con nosotros; con solo escucharlos y darles nuestro punto de vista, fundamentado en la norma y en la experiencia, los problemas se suavizan o se resuelven y evitan a la Administración entrar en procesos burocráticos.

El día a día demuestra que, como dice el Informe 2013 sobre el estado del sistema educativo del Consejo Escolar del Estado, la Inspección Educativa se ocupa, principalmente, de tareas burocráticas (p. 560). Esta burocratización está mal vista tanto por los inspectores como por los centros que desean tener una inspección donde pesen más las funciones de colaboración y asesoramiento, e incluso de supervisión.

Intervenimos muy poco en los procesos de evaluación de los centros y del profesorado y nada en los procesos de diseño de las evaluaciones.

Somos poco conocidos para la sociedad, los medios de comunicación solo nos nombran cuando intervenimos en casos de acoso, violencia de género, abusos a menores, etc. Apenas se nos tiene en cuenta para opinar sobre el estado del sistema educativo, para informar sobre cuestiones técnicas, innovaciones, aspectos legales, etc.

Es escasa la autoevaluación de nuestra función, con lo cual es bastante complicado proponer mejoras o cambios sustanciales en nuestro quehacer cotidiano que, además, solo dependen de nosotros mismos o de las áreas de las que formamos parte, estos procesos de cambio hacia la mejora no necesitan el sustento normativo por los que podríamos abordarlos con inmediatez. Nunca nos preguntamos ¿qué podríamos hacer para mejorar el sistema educativo? Dejamos en manos de la Administración educativa la regulación de nuestras funciones y atribuciones, como es lógico, pero no debemos olvidar que la inspección corre el riesgo de ser utilizada políticamente, como demuestran muchas de las investigaciones y publicaciones al respecto, y no tenemos en cuenta factores que sí están de nuestra mano para contribuir en la mejora del sistema como por ejemplo liderar procesos de innovación, demostrar en nuestras actuaciones que creemos en la posibilidad de hacer un sistema educativo justo, con igualdad de oportunidades, equitativo e inclusivo (Romero, 2018).

Se cuenta poco con la inspección para liderar procesos de formación con el profesorado, sin embargo, cuando los llevamos a cabo en nuestros centros la evaluación generalizada del profesorado es muy positiva pues conocemos de primera mano los problemas del sistema y las posibles soluciones que se emprenden en otros centros y que podemos extrapolar. Tenemos una rica visión comparativa.

Una última reflexión de lo que es el día a día de una inspectora de educación es que existe una elevada carga de trabajo, totalmente desconocida de cara al exterior; de hecho, una compañera, recientemente incorporada a la inspección proveniente de un equipo directivo de un instituto, señalaba «que no se hacía ni idea de todo lo que se lleva en inspección» esta enorme carga de trabajo nos hace, a veces, ir demasiado deprisa, sin procesos de reflexión, apagando fuegos y, como consecuencia, alejándonos de los verdaderos fines de nuestro trabajo. La Administración nos solicita, frecuentemente, 
informes, datos o respuestas con tal inmediatez que nos obliga a dejarlo todo y a posponer nuestras actuaciones programadas.

\section{Bibliografía}

Consejo Escolar del Estado (2013) Informe 2013 sobre el estado del sistema educativo. Secretaría General Técnica, Centro de Publicaciones. Ministerio de Educación, Cultura y Deporte.

Esteban Frades, S. (20I4) La Inspección de Educación. Historia, pensamiento y vida. Oviedo: ADIDE. KRK

López del Castillo, M. ${ }^{\text {a T. }}$ (1993) La inspección que he vivido. En E. Soler (coord.) Fundamentos de supervisión educativa. Madrid: La Muralla.

Moriña, A. (20I6) Investigar con historias de vida. Madrid: Narcea.

Romero Ureña, C. (2018) Inspección e inclusión educativa. Revista Digital de Educación del FEAE-Aragón, 24.

Ruiz Olabuénaga, J. I. (20I2) Historias de vida. En Metodología de la investigación cualitativa. Bilbao: Universidad de Deusto. 